\title{
Cheaper and More Haircuts After VAT Cut? Evidence from the Netherlands
}

\author{
Egbert Jongen $^{1}$ (D) $\cdot$ Arjan Lejour $^{2}$ (D) $\cdot$ \\ Gabriella Massenz $z^{3}$
}

C Springer Science+Business Media, LLC, part of Springer Nature 2018

\begin{abstract}
We study the effect of the reduction in the VAT rate on hairdresser services from 17.5 to $6 \%$ in the Netherlands in January 2000. Following Kosonen (J Public Econ 131:87-100, 2015), we use differences-in-differences to estimate the effects of this reform, with beauty salons as the main control group. In our preferred specification, we find close to full pass-through of the VAT cut into lower prices. However, we find no statistically or economically significant effect on the volume of sales or employment.
\end{abstract}

Keywords VAT reform · Hairdressers $\cdot$ Differences-in-differences $\cdot$ Netherlands

JEL Classification $\mathrm{C} 33 \cdot \mathrm{H} 22 \cdot \mathrm{H} 25$

\begin{abstract}
We are grateful to Hub van den Akker, Ivo Gorissen and Arjan van Loon of Statistics Netherlands for additional information on the data used in this paper. Furthermore, we have benefited from comments and suggestions by Jan van Ours (editor), two anonymous referees and Leon Bettendorf, Jarkko Harju, Pierre Koning, Tuomas Kosonen, Daniël van Vuuren, seminar participants at CPB Netherlands Bureau for Economic Policy Analysis, participants of the OFS Workshop on Indirect Taxation March 2017 in Oslo and the MaTax Conference September 2017 in Mannheim. Remaining errors are our own.
\end{abstract}

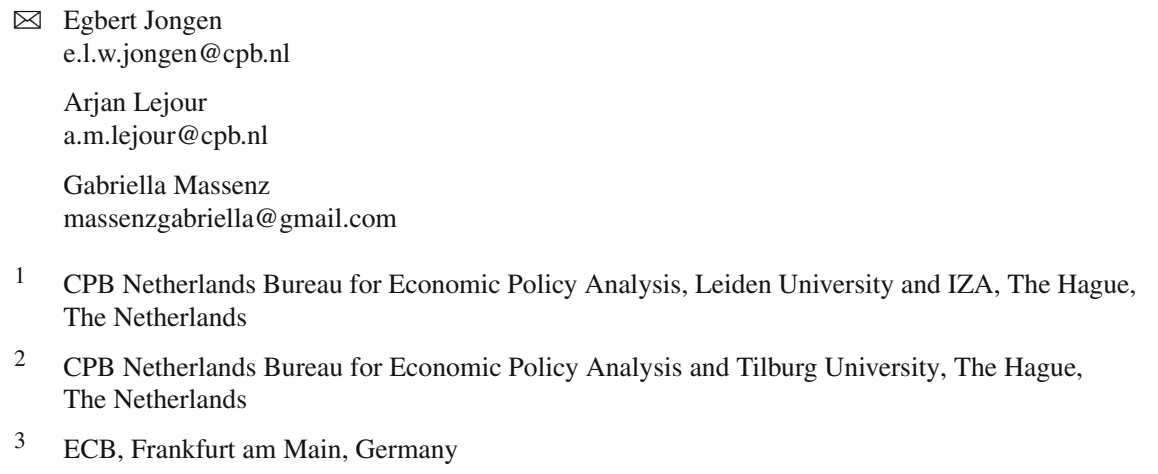




\section{Introduction}

Reduced value added tax (VAT) rates on labour intensive services can be motivated by efficiency arguments. ${ }^{1}$ The theoretical literature on optimal commodity taxation concludes that VAT rates should be lower on goods and services that have a relatively high demand elasticity, so as to minimize tax distortions (Ramsey 1927; Diamond and Mirrlees 1971). The demand elasticity might be relatively high for labour intensive services because they can shift between the formal and informal sector and could also be close substitutes for household production (Copenhagen Economics 2008). These considerations suggest that VAT rates on labour intensive services should be relatively low. As a result, it might be expected that a VAT cut for these services will foster demand and employment. In 1999, the European Commission (EC) decided to allow Member States of the European Union (EU) to experiment with reduced VAT rates for a number of labour intensive services, so as to reduce informal employment and stimulate formal employment (European Commission 1999). Following this decision, many EU countries, including the Netherlands, reduced VAT rates on selected labour intensive services.

Several papers have studied the pass-through of VAT cuts into lower prices, with mixed results ranging from no pass-through to more than full pass-through (IFS et al. 2011). However, little is known on the effect of VAT cuts on the amount of labour intensive services and employment. A recent quasi-experimental study by Kosonen (2015) on a VAT cut for hairdressers in Finland suggests that there was hardly any effect on the amount of labour intensive services. To the best of our knowledge, there is no quasi-experimental study on the employment effects of VAT cuts for labour intensive services. This is surprising given that higher formal employment was an explicit goal of the EU directive on reduced VAT rates for labour intensive services.

In this paper we study the effect of the VAT cut for hairdressers in the Netherlands on prices, the volume of sales, employment in persons and employment in full-time equivalents. In 2000, the VAT rate in the Netherlands on selected labour intensive services, including services by hairdressers, was reduced from 17.5 to $6 \%$. $^{2}$ However, the VAT rate on related labour intensive services, including services by beauty salons, was left unchanged. This reform creates a natural experiment that can be exploited to investigate the effect of the VAT cut on hairdressing services.

Our empirical strategy follows Kosonen (2015). Specifically, we compare outcomes for hairdressers following the VAT rate reduction to those of similar services taxed at the standard rate, presenting both graphical evidence and regression results. Our main control group consists of beauty salons. We choose this control group because both professions are labour intensive and provide individual services in a similar working environment. Both services require some degree of specialization, and one cannot easily switch from one type of service to the other. We use differences-in-differences to investigate the causal effect of the reform. By taking a double difference, this

\footnotetext{
1 See IFS et al. (2011) for an overview.

2 Next to services provided by hairdressers, the VAT cut also applied to plastering, painting and glazing services for houses more than 15 years old; bicycle repair services; repair of footwear and leather wear and repair of clothing and household linen. See Sect. 2 for more details.
} 
method controls for a group fixed effect and common time effects (due to e.g. the business cycle) in the outcomes for hairdressers and beauty salons. We use monthly survey data on average prices, sales and volume ${ }^{3}$ and annual firm-level survey data on sales, employment in persons and employment in full-time equivalents from Statistics Netherlands.

Our main findings are as follows. First, we find close to full pass-through of the VAT cut to consumers in the form of lower prices. In our preferred specification, we estimate a drop in prices following the reform of $-6.4 \%$, which is $80 \%$ of what full pass-through would imply. The effect is immediate and does not fade away in the years following the reform. Second, using the monthly survey data we find an effect on the volume of sales that is statistically and economically insignificant. Finally, using the annual firm-level survey data we do not find a statistically and economically significant effect on the employment in persons, employment in full-time equivalents and the volume of sales, though the standard errors are relatively large due to the small sample size. The results suggest that competition among hairdressers is relatively strong, which leads to the near full pass-through of the VAT cut into prices, but that the demand for hairdressing services at the sector level is rather inelastic.

We make two contributions to the literature. First, we study the effect of a VAT cut on labour intensive services on the volume of sales and employment in persons and in full-time equivalents. Indeed, promoting (formal) employment was one of the main goals of the EC directive. This paper complements the few papers that also use quasiexperimental methods to study the effect of a VAT cut on labour intensive services on quantities. Our findings on the volume of sales are consistent with Harju and Kosonen (2014) and Kosonen (2015). Harju and Kosonen (2014) study the impact of changes in the VAT rates applied to restaurant meals in Finland in 2010 and in Sweden in 2012 following the implementation of an EC directive. The authors compare output in restaurants in the affected country to neighboring countries and to similar industries in the same country using differences-in-differences. They find no significant impact of the reforms on the quantity of meals traded, for which they use the proxy of restaurants sales. Similarly, Kosonen (2015) uses sales as a proxy for output to establish the effect of lower VAT rates for hairdressers on the quantity of services traded, using a VAT reduction in Finland in 2007. He finds no significant effect on output. We also do not find an effect of the VAT cut on quantities, nor on the volume of sales or on the level of employment.

Second, we contribute to the broader literature that considers the pass-through of VAT changes into prices. Overall, there is no consensus yet on the effect of the implementation of reduced VAT rates on prices, except that the pass-through depends on the market structure. IFS et al. (2011) give an overview of the empirical results found by the literature and report effects ranging from zero pass-through to more than full pass-through. Benedek et al. (2015) analyze the effect of various VAT reforms on prices in 17 Euro Area countries between 1999 and 2013. The authors estimate close to full pass-through for changes in the standard VAT rate, but they find essentially zero pass-through for reclassifications of consumer goods and services between standard,

\footnotetext{
3 Unfortunately, the micro survey data underlying the monthly price, sales and volume index for the period around the reform are no longer available.
} 
reduced and zero rates. These results are the average effects of many VAT changes in the Euro Area. In contrast to Benedek et al. (2015), we find nearly full pass-through of a reclassification from the standard to the reduced tariff rate. Vrijburg et al. (2014) also find full pass-through for two increases of the general VAT rate in the Netherlands. Regarding labour intensive services, Harju and Kosonen (2014) find that restaurants reduced prices by about a quarter of what full pass-through to consumer prices would have implied, and Kosonen (2015) estimates a pass-through of about a half for the VAT cut for hairdressers in Finland. In contrast to Harju and Kosonen (2014) and Kosonen (2015), our results suggest a much larger pass-through.

The outline of the paper is as follows. Section 2 outlines the Dutch reform and discusses theoretical predictions. Next, Sect. 3 presents the empirical methodology. Section 4 describes the data used and presents summary statistics of the firm-level data. Graphical evidence and estimation results are given in Sect. 5. Section 6 discusses our findings and concludes.

\section{The Reform and Theoretical Predictions}

EU law requires Member States to levy value added taxes on consumption while making provisions for VAT exemptions and tariff reductions for specific goods and services. In the late 1990s, both at the European and Member State level, policymakers discussed the desirability of reduced rates for labour intensive services. Following this debate, seven labour intensive service sectors were indicated to be eligible for VAT reductions by an EC directive in 1999 (European Commission 1999). The provision allowed Member States to experiment reduced rates on labour intensive services for a limited period of 3 years, with the aim to foster formal employment and to reduce informal employment in these services.

By the end of 1999, the Dutch government chose to implement reduced VAT rates for 5 labour intensive services: (i) hairdressers, (ii) plastering, painting and glazing of houses older than 15 years, (iii) bike repair, (iv) shoes and leather wear repair, and (v) clothes and household linen repair. On the 1st of January of 2000, the VAT rate changed from the standard $17.5-6 \%$ in the selected services. The initial period of 3 years was subsequently extended to allow for a more careful assessment of the results of the experiment (European Commission 2002). ${ }^{4,5}$ In 2009, the EC made the directive permanent, but Member States still have the possibility to end the VAT rate reduction in their own country (Seely 2016).

\footnotetext{
4 An early global evaluation report by the European Commission (2003) found no significant effects of the reforms in Member Countries on informal nor on formal employment, but did not use micro data or differences-in-differences.

5 For instance, following the European Commission (2003) report, the EC adopted a proposal for a directive introducing a general review of reduced VAT rates in the EU. However, as by the time of the deadline of the experiment a unanimous decision on the treatment of such rates had not been reached yet, the time frame of the reform was extended to avoid legal uncertainty. The deadline was subsequently prolonged due to concerns regarding new Member Countries' rights to experiment with reduced rates. See European Commission (2004) for a short summary of the developments up to 2004.
} 
Ideally, one would want to study the effect of the reform on all five services affected by the Dutch reform. However, in the case of bike repair and of plastering, painting and glazing services, data from EIM (1998) shows that the portion of sales affected by the reduced VAT rate would be less than $25 \%$. As the data used for the analysis does not allow us to identify sales according to the VAT rate applied, it is hard to estimate the effect of the reform on these services. Regarding clothing and household linen repair, micro data on this type of service is not available. Finally, in the case of shoes and leather wear repair, we could not find a plausible control group with common time effects. Therefore, the focus of the paper lies in estimating the effect of the reform on outcomes in hairdressing services — the treatment group — by comparing them to similar services unaffected by the reform, beauty salons-the control groupfollowing Kosonen (2015). ${ }^{6}$

The overview above shows that the topic was already debated for some years, and we may be concerned that hairdressers anticipated the reform. However, for a long time it was unclear when the EU would decide on the experiment and which sectors would be affected by the reform. First, the EU had to determine which sectors could be included in the experiment. Second, national governments had to decide whether they wanted to join the experiment and in which sectors. Hairdressers could be included, but this remained unclear until the reform was announced in the Fall of 1999. Meanwhile, hairdressing services and tasks were reclassified according to a collective labour agreement on January 1st, 1999. Inspection of the wage schedules of the old and new function classification (CAO 1998) shows that the new wages were about $2 \%$ higher in January 1999, abstracting from the yearly wage increase. This suggests that at least a substantial share of the price increase in 1999 (see Fig. 1a below) was due to the wage increase. Due to the uncertainty of the outcome of the political debates at various levels, we argue that the price increase in 1999 can hardly be interpreted as an anticipation effect of the VAT cut that happened a year later, in 2000.

For the Dutch reform, we can derive that prices of services with the reduced VAT rate would have been nearly $10 \%$ lower in the case of full pass-through. The proportional change in consumer prices after the reform $\Delta P$ can be written as:

$$
\Delta P=\frac{P^{a}-P^{b}}{P^{b}} * 100=x \%,
$$

where $P^{b}$ is the pre-reform price and $P^{a}$ is the post-reform price. Keeping producer prices $\alpha$ constant, consumer prices can be written as $P^{b}=\alpha * 1.175$ and $P^{a}=$ $\alpha * 1.06$. Hence, we obtain a proportional change in prices of $-9.8 \%$. This calculation assumes that hairdressers only sell labour intensive services whereas hairdressers also sell goods and services for which the reduced rate does not apply (e.g. the sale of hair-care products). According to EIM (1998), in the pre-reform period, services by hairdressers with the reduced VAT rate constituted $79 \%$ of their total sales. Hence, for all services and products sold by hairdressers we would expect an $8 \%$ decrease in prices in the case of full pass-through. Actually, things are more complicated than this.

\footnotetext{
6 EIM (1998) estimates the 'ex ante' (absent behavioural responses) loss in tax revenue due the VAT reduction for hairdressing services at approximately 80 million euro per year.
} 
Firms are only obliged to pay VAT when the total amount of VAT to be paid exceeds a threshold (Kleinondernemersregeling in Dutch). This VAT threshold is relatively low: 1883 euro. However, because of the reform more firms did not have to pay VAT anymore. ${ }^{7}$ Unfortunately, our sample is too small to look at the effects on these subgroups of firms. ${ }^{8}$

According to standard incidence theory, the extent of pass-through of a VAT cut into prices depends on the price elasticities of demand and supply (Harju and Kosonen 2014). ${ }^{9}$ Specifically, the pass-through is given by: $\rho=\epsilon_{s} /\left(\epsilon_{S}-\epsilon_{d}\right)$, where $\epsilon_{S}$ is the price elasticity of supply and $\epsilon_{d}$ is the price elasticity of demand. When the price elasticity of supply is relatively high, or the price elasticity of demand is relatively low, pass-through will be high. Specifically, in the special cases of $\epsilon_{s} \rightarrow \infty$ or $\epsilon_{d} \rightarrow 0$, there is full pass-through.

Lower prices may induce extra demand for hairdressing services. This will increase the volume of sales, which in turn will increase employment. This could be in terms of additional persons employed or in terms of more working hours per employed person. As many hairdressers work part-time, it is relatively easy to expand the number of hours worked per week. On the other hand, attracting more employees involves fixed costs. Because the VAT cut was announced to be temporary, firms may have been reluctant to hire additional employees. They may have responded more in hours worked per week. Next to stimulating overall demand for hairdresser services, the VAT cut may also have stimulated hairdressing services to move from the informal to the formal sector. Indeed, this was one of the main objectives of the reform. Hence, theory suggests a positive effect on formal employment, at least in hours worked per week.

\section{Empirical Methodology}

We use differences-in-differences (DID) to estimate the effects of the reform on prices, employment and sales. ${ }^{10}$ In the DID approach we estimate the impact of a policy reform by taking a double difference between treatment group and control group in the outcome variable. First, we take the difference in the outcome variable between the treatment group and the control group after the reform. Second, we subtract the difference in the outcome variable between the treatment group and the control group before the reform. In this way we control for the time-invariant difference between treatment and control group and for common time effects in the outcome variable.

\footnotetext{
7 Specifically, before the reform of 2000, firms with taxable sales of 1883/0.175 $=10,760$ euro did not have to pay VAT, but could also not deduct VAT on inputs. After the reform of 2000, firms with taxable sales of $1883 / 0.06=31,383$ euro did not have to pay VAT. Hence, firms with taxable sales $<10,760$ euro did not experience a drop in their VAT rate, whereas firms with taxable sales $>10,760$ euro and $<31,383$ euro experienced a drop in their VAT rate of $17.5 \%$ as opposed to $11.5 \%(17.5-6 \%)$.

${ }^{8}$ In order to investigate potential bunching, we plotted histograms of taxable sales around the VAT thresholds before and after the reform, but these did not show any signs of bunching below the threshold.

${ }^{9}$ Standard incidence theory assumes that the incidence of VAT rate changes is symmetric for increases and decreases in the VAT rate. However, a recent study by Benzarti et al. (2017) suggests that the incidence might be asymmetric, with lower pass-through for VAT cuts than for VAT rises.

${ }^{10}$ For a general introduction to the differences-in-differences methodology see e.g. Angrist and Pischke (2008).
} 
Our treatment group consists of hairdressers and our main control group consists of beauty salons. As stressed by Kosonen (2015), hairdressers and beauty salons are likely to develop similarly. Both services are labour intensive and are provided to one customer at a time in a similar business space. Moreover, both services require some degree of specialization, which is not easily interchangeable. Both are studies at the vocational level in the Netherlands, which take students several years to complete. There are hardly any enterprises which combine both services; only $1 \%$ of the hairdresser sales consists of beauty treatments in 2009 (Hoofdbedrijfsschap Ambacht 2009). Hairdresser shops are started by hairdressers who were previously employed by other hairdressers and usually have no additional skill qualifications. The types of services also differ, and cannot be viewed as substitutes (Kosonen 2015). There may be some complementarity, but the isolated activities of both services are not consistent with this. Although we should note that this conclusion is based on qualitative information and survey data, there are no estimated cross-price elasticities which could give more quantitative evidence on this. Finally, both hairdressers and beauty salons provide services that are partly a necessity and partly a luxury. Below, we also formally test whether beauty salons are a valid control group. Specifically, we test the assumption of common time effects using pre-reform placebo treatment dummies and consider whether the treatment effects are robust to the inclusion of differential trends between the treatment and control group.

As noted above, a complication for the DID analysis is the function reclassification in the hairdressers sector in 1999, which raised labour costs. In our preferred specification we treat this as a 'structural break' in the outcome variable for the treatment group from 1999 onwards. However, we also consider results where we treat 1999 as another treatment year, to investigate the effect of this alternative assumption on the results.

Our monthly outcome variables are the log of the price index, sales and the volume of sales. By taking logs we implicitly assume common time effects in percentage terms. The treatment effects can then readily be interpreted as effects in percentages (when multiplied by 100). The estimation equation for the monthly indices $Y$ is:

$$
\log Y_{g, t}=\beta_{t}+\beta_{m}+\beta_{g}+\beta_{g, t}(t-1996.4)+\delta_{b} S B 1999+\delta_{p} D I D_{g, t}+\varepsilon_{P},
$$

where $g$ indicates the group (treatment or control) and $t$ time. $\beta_{t}$ are year fixed effects, $\beta_{m}$ are month fixed effects ${ }^{11}, \beta_{g}$ is a group dummy which is 1 for hairdressers and 0 for beauty salons and $\beta_{g, t}$ captures group specific trends based on a monthly unit. ${ }^{12}$ $S B 1999$ is the dummy for the structural break, which is 1 for hairdressers in 1999 and beyond, with parameter $\delta_{b}$. DI $D_{g, t}$ is the treatment dummy, which is 1 for hairdressers after the reform-i.e. for 2000 and beyond-and $\delta_{p}$ is the main parameter of interest, which captures the average impact of the reform on hairdressing services. In an extension we also allow for pre-reform placebo treatment dummies, which equal 1 for hairdressers in a pre-reform year, and for treatment dummies for individual years

\footnotetext{
11 This specification assumes similar month fixed effects for all years. Allowing for a full set of month-year fixed effects generates results that are almost identical to our base specification with separate year and month fixed effects (available on request).

12 That is, 1996.4 stands for April 1996, 1996.5 for May 1996 and so on.
} 
after the reform, to study short-run versus medium-run responses. ${ }^{13}$ The error term accounts for heteroscedasticity and group-specific first-order autocorrelation. ${ }^{14}$

For employment in persons, employment in full-time equivalents and sales we have annual firm-level panel data. The estimation equation for these outcome variables $Y$ is:

$$
\log Y_{i, g, t}=\gamma_{t}+\gamma_{i}+\gamma_{g, t}(t-1997)+\gamma_{b} S B 1999+\delta_{y} D I D_{g, t}+\epsilon_{Y},
$$

where $i$ indicates firm $i, \gamma_{t}$ are year fixed effects, $\gamma_{i}$ is a firm fixed effect ${ }^{15}$ (since firms never change between hairdressers and beauty salons in the data, the group fixed effect is absorbed by the firm fixed effect) and $\gamma_{g, t}$ captures group specific time trends. $S B 1999$ is again the dummy for the structural break, which is 1 for hairdressers in 1999 and beyond, with parameter $\gamma_{b} . D I D_{g, t}$ is the treatment dummy which is 1 for hairdressers in 2000 and beyond and $\delta_{y}$ is the corresponding parameter. In an extension we also allow for pre-reform placebo treatment dummies and consider treatment dummies for individual years after the reform for these outcome variables. For the firm level estimations we use robust standard errors. ${ }^{16}$

\section{Data}

We use two types of survey data in the empirical analysis. First, we use monthly survey data on the consumer price index, the sales index and the volume of sales index, which is available at the 5-digit level industrial classification codes on Statline of Statistics Netherlands. ${ }^{17}$ Our treatment group is hairdressers and our preferred control group is beauty salons. ${ }^{18,19}$ The monthly indices relate to all services

\footnotetext{
13 Note that we assume that the full effect of the 1999 function reclassification occurs in 1999. When there is a delayed response to the function reclassification, the treatment effect of the 2000 reform will also pick up this delayed response. However, the empirical results suggest that the full treatment effect of the 2000 reform on prices already occurred in the first year, providing no evidence for a delayed response. Furthermore, the treatment effect on the volume of sales seems, if anything, to decline over time, whereas a delayed reponse to the 1999 function reclassification would suggest an increasing pattern over time, as this effect fades away.

${ }^{14}$ Using the Stata package xtpcse.

15 A Hausman test rejects that the individual firm effects are adequately modeled using a random effects specification (available on request).

16 We also estimated Eq. (3) using cluster-robust standard errors, clustered at the firm level. However, this resulted in smaller rather than larger standard errors (available on request). We prefer to be conservative and report the larger (robust) standard errors, as suggested by Angrist and Pischke (2008). Furthermore, the conclusions are robust across the alternative specifications for the standard errors, the treatment effects are still insignificant with cluster-robust standard errors.

17 The price, sales and volume indices for hairdressers are taken straight from Statline, www.statline.nl. For beauty salons, the price index of beauty treatments and the sales index of beauty salons are taken straight from Statline. Following the expert advice of Statistics Netherlands we deflate the sales index of the beauty salons with the beauty treatment price index to generate the volume index for beauty salons.

18 Hairdressers correspond to SBI-1993 code 93021, and beauty salons correspond to SBI-1993 code 93022.

19 As an alternative control group we consider laundry services, for which similar monthly indices are available.
} 
and products sold by hairdressers and all services and products sold by beauty salons. Consistent series are available starting from April 1996 up to and including December 2002. We also have data on the monthly price index for haircuts for women, the monthly price index for haircuts for men and children and beauty treatments from Statline, and these data are available for a longer period (May 1996-December 2005). We use this alternative price index to study whether the treatment effect on prices was different in the period after 2002 when compared to the period 2000-2002. Unfortunately, we do not have monthly data series for sales and the volume of sales for haircuts for women or for haircuts of men and children.

Second, we use annual firm-level survey data on employment and sales from the Production Statistics dataset of Statistics Netherlands. The Production Statistics consist of survey data collected from firms in December of each year. First, a number of firms are drawn from the firms registered at the Chamber of Commerce. The same firms are interviewed in subsequent years, hence it is panel data. However, the attrition rate is quite high (as is typical for firm level data), in the order of $30 \%$ each year. Firms that drop out are replaced by others drawn from the sample of those registered at the Chamber of Commerce. The Production Statistics contain data on the total number of employed persons (including the owner) and the total number of employed persons expressed in full-time equivalents (including the owner) per firm. The Production Statistics also contain firm level data on sales. Our treatment and control groups are again identified by the 5-digit level industrial classification codes.

Firm-level data is available for the period 1993-2008. However, we can only use data for the period 1995-2002, as significant changes were made in the questionnaire before and after that period. Another important issue concerns the quality of the data. Part of the observations in the dataset are imputed, because firms do not return the questionnaire. Unfortunately, for the years 1996-1999 we do not know which values are imputed. To mitigate this problem, we exploit the panel nature of the dataset and we drop all firms for which we know that data is imputed at least once in the years 1995, 2000, 2001 or 2002. To improve data quality and consistency, we perform some further data cleaning actions. We drop observations for which population weights equal zero (mostly firms that went bankrupt) and we exclude observations with zero employed persons (or zero employed persons in full-time equivalents when we look at employed persons in full-time equivalents). In addition, we only include observations with positive sales. ${ }^{20}$ Finally, to limit period-specific firm heterogeneity we include only firms for which there is at least one observation before the reform and at least one observation after the reform. ${ }^{21,22}$ In the main analysis we focus on a balanced panel

\footnotetext{
20 There are no negative values in the data set, and observations with zero sales are likely to correspond to inactive firms.

21 Unfortunately, our small sample size precludes a meaningful analysis of entry and exit of firms due to the reform.

22 We start with 5945 observations for the period 1995-2002. After we drop observations on firms that have imputed values we are left with 4077 observations. When we then drop observations on firms with zero population weights, employment or sales this reduces to 3398 observations. Next, when we keep only firms observed at least once before and at least once after the reform, our sample size reduces to 1396
} 
Table 1 Summary statistics: balanced panel of firms 1997-2002

\begin{tabular}{|c|c|c|c|c|}
\hline & \multicolumn{2}{|c|}{ Treatment group } & \multicolumn{2}{|c|}{$\begin{array}{l}\text { Differences in means (treatment } \\
\text { group-control group) }\end{array}$} \\
\hline & \multicolumn{2}{|c|}{$\begin{array}{l}\text { Pre-reform } \\
1997-1999\end{array}$} & \multirow[t]{2}{*}{$\begin{array}{l}\text { Pre-reform } \\
1997-1999\end{array}$} & \multirow[t]{2}{*}{$\begin{array}{l}\text { Post-reform } \\
2000-2002\end{array}$} \\
\hline & Mean & SD & & \\
\hline Log employees & 1.229 & 0.874 & 1.152 & 1.173 \\
\hline Log employees in FTE & 1.000 & 0.805 & 0.923 & 0.987 \\
\hline Log sales & 4.327 & 1.142 & 2.039 & 1.934 \\
\hline
\end{tabular}

Own calculations using the Production Statistics of Statistics Netherlands. Hairdressers are the treatment group and beauty salons the control group. The treatment group has 222 observations and the control group has 54 observations, equally split between pre- and post-reform in both groups

of firms for the period 1997-2002, i.e. observed in the 3 years before and the 3 years after the reform. Extending the balanced panel to more periods results in a sharp drop in the observed number of firms. Below we also present results for the unbalanced panel of firms observed at least once before and after the reform. However, large firms are more likely to survive in the panel after the 2000 reform, resulting in an upward shift in the outcome variables for both the treatment and control group. This is why we prefer the estimates for the balanced panel.

Table 1 shows averages for the micro data for the balanced sample of firms. The first column of the table reports mean values for hairdressers in the period before the reform (1997-1999). The second part of the table reports differences in means between hairdressers and beauty salons before (1997-1999) and after (2000-2002) the reform. The descriptive statistics suggest a small, positive treatment effect for employment in persons and in full-time equivalents, but a negative treatment effect for sales. ${ }^{23}$

\section{Results}

We first present the results for the monthly price, sales and volume index and subsequently present our findings for employment and sales for the balanced panel of firms.

Figure 1a shows the price index for the treatment and control group in the years before and after the reform. The solid black line is the control group and the dashed red line is the treatment group. The last month before the reform is marked by the solid vertical line. The prices of hairdressers and beauty salons move more or less in tandem up to January 1999, when there is a steep upward jump in the prices of hairdressers, due to the wage increases following the collective labour agreement (see

\footnotetext{
Footnote 22 continued

observations. Finally, restricting the sample to a balanced panel for the period 1997-2002 we are left with 276 observations.

23 Note that sales are the product of volume and price. When the effect of the VAT reform on the price is negative and there is hardly any effect on the volume of sales, the effect on sales will be negative.
} 
(a)

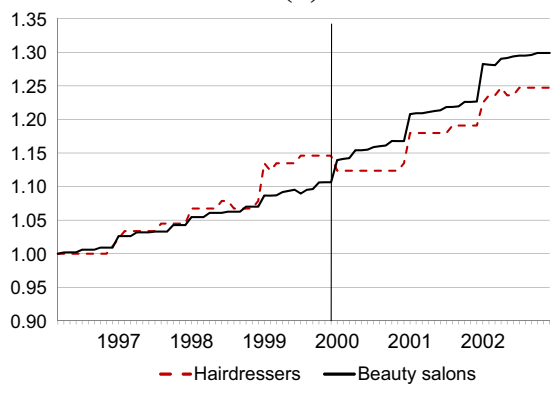

(c)

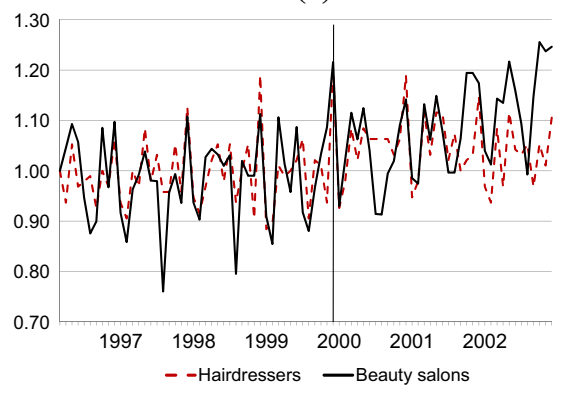

(b)

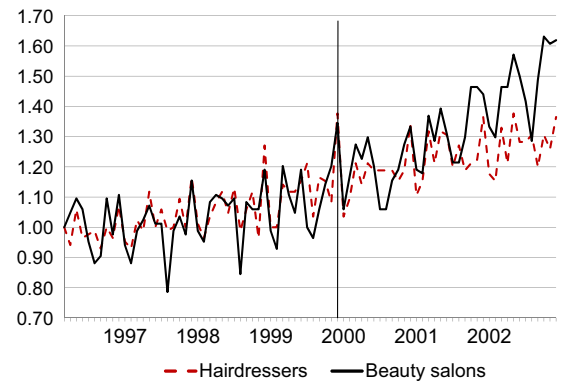

(d)

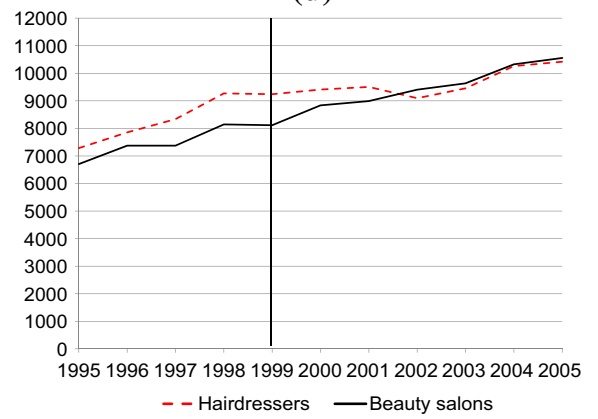

Fig. 1 Plots aggregate data. a Monthly price index. b Monthly sales index. c Monthly volume index. d Annual number of firms. Notes Data from Statline of Statistics Netherlands. The vertical line marks the last period before the reform

the discussion in Sect. 2). In the regression analysis we therefore include a dummy for a structural break from 1999 onwards. Next, in January 2000, at the start of the reform, we see a downward jump in prices of hairdressers, and the price index drops below the price index of beauty salons, consistent with pass-through of lower VAT rates to lower consumer prices. Subsequently, in all periods after January 2000, the price index of hairdressers remains below the price index of beauty salons, showing a persistent pass-through. Figure 1b, c show the indices for sales and the volume of sales, respectively. Note that the index for volume is the index for sales divided by the index for price. Both sales and volume show a similar pattern for the treatment and control group before the reform, with a clear seasonal pattern in both series (less business during the Summer and more business in December). After the reform, sales and volume of hairdressers seems to grow slower than sales and volume of beauty salons. Hence, there is no visual positive treatment effect on these outcome variables. Finally, Fig. 1d shows annual data on the number of firms. ${ }^{24}$ There is no apparent evidence of additional firm entry or reduced firm exit after the VAT cut for hairdressers. Indeed, the number of hairdressing firms seems to decline rather than to increase relative to the number of beauty salons following the 2000 VAT cut.

\footnotetext{
24 Source: Statline of Statistics Netherlands.
} 
Next, we present regression results, see Table 2. We estimate the model in Eq. (2). Recall that we use the log of the index as the dependent variable, hence the treatment effects should be interpreted as percentage effects (when multiplied by 100). Column (1) presents DID estimates for the price index with year and month fixed effects, a dummy for the structural break in 1999, a group dummy for hairdressers and a single treatment dummy for hairdressers for the period 2000-2002. This suggests a statistically significant negative treatment effect of $-6.4 \%$, which is quite near to what full pass-through would imply $(-8 \%) .{ }^{25}$ Column (2) uses the same specification with the log of the sales index as dependent variable. We find a drop in sales of $-10.2 \%$, again statistically significant. Column (3) then presents the results for the log of the volume index. This suggests a small negative but statistically insignificant treatment effect on the volume of sales. These results suggest that the drop in price following the reform did not result in an increase in the number of quantities traded. Columns (4)-(6) give the estimation results when we include year-specific treatment effects for 2000, 2001 and 2002. We find that the drop in prices is immediate and stays rather constant after 2000. The negative effect on sales seems to grow over time, whereas the effect on volume goes from slightly positive to slightly negative and then more negative in 2002. Hence, there is no evidence of a delayed positive response in the number of quantities traded, quite the contrary.

A number of additional robustness checks for the effect on prices are given in Table 3. Additional robustness checks for sales and volume are given in Jongen et al. (2017), which we briefly discuss as well. Including a pre-reform placebo dummy for 1998 in column (2) results in a coefficient that is positive and statically significant but relatively small for prices. This might hint at small trend differentials in the price development of services offered by hairdressers and beauty salons. The coefficient of the placebo for sales and volume is small and statistically insignificant (Jongen et al. 2017, Tables A.2, A.3). However, including a differential trend for the treatment and control group results in a treatment effect for prices that is very similar to the base specification, column (3). Including a differential trend for the treatment and control group in the specifications for sales and volume results in a less negative treatment effect for sales and a small positive but still statistically insignificant effect for volume (Jongen et al. 2017, Tables A.2, A.3). Hence, differential trends in the volume of sales may explain the puzzling negative though insignificant treatment effect for the volume of sales, but still does not result in a statistically and economically significant treatment effect. ${ }^{26} \mathrm{Next}$, we consider separate effects for women hairdressers and man and children hairdressers, column (4) and (5). The advantage of these data series is that they are available for a longer period, up to December 2005. The regression results are also very similar to the base, both for women hairdressers and men and children hairdressers. Furthermore, in Tables A.4 and A.5 in Jongen et al. (2017) we show that

\footnotetext{
25 We also find a positive statistically significant structural break in 1999 for prices of hairdressers.

26 Although we consider it unlikely (see the discussion in Sect. 2), it could be the case that the price increase in 1999 is not a structural break, but an anticipation effect of the lower VAT rate in 2000. To see how this would affect the results, Tables A.1, A.2 and A.3 in Jongen et al. (2017) present the results obtained when we drop the structural break dummy and extend the treatment dummy to the period 1999-2002 (instead of 2000-2002). The treatment effect on prices is then positive but small, which seems rather counterintuitive, and the treatment effect on sales and the volume of sales are still negative, though less negative.
} 


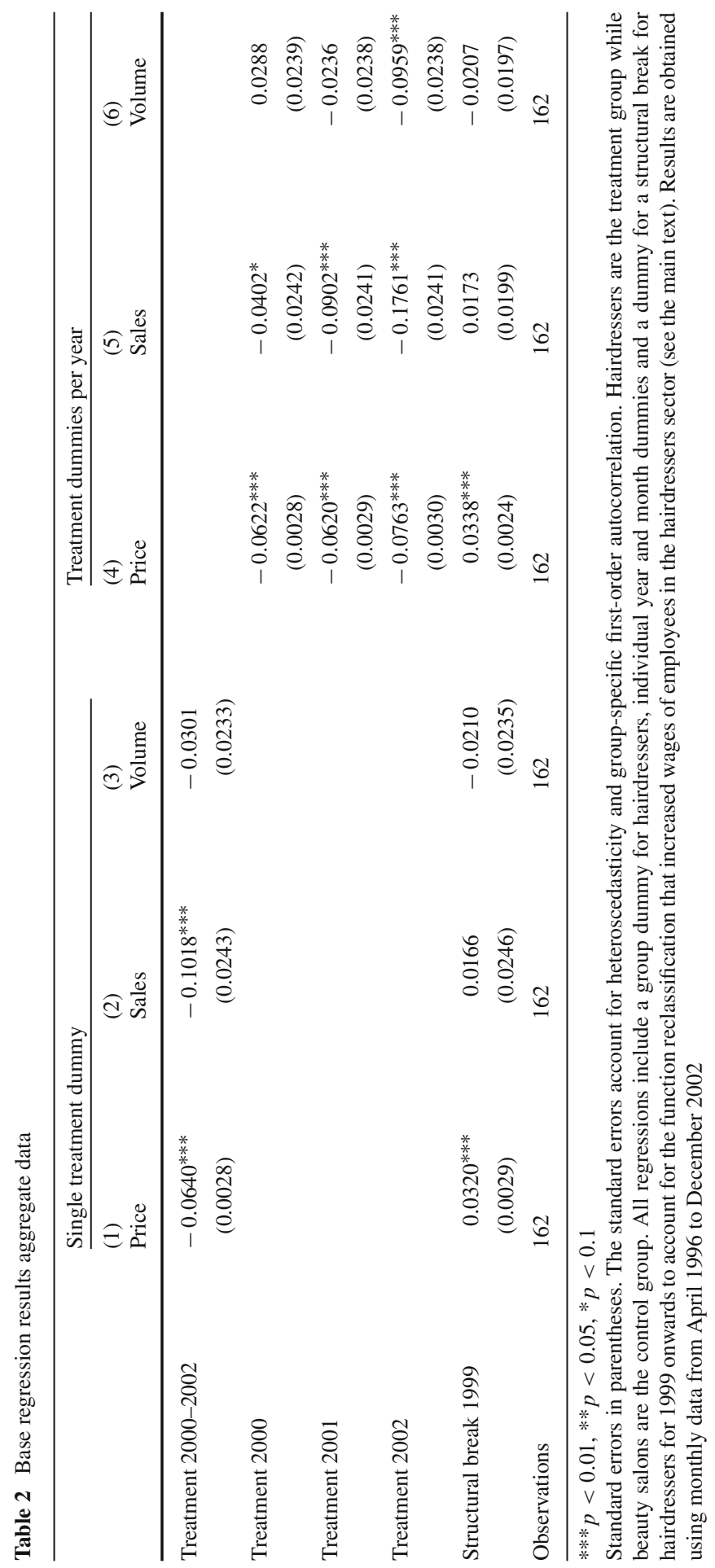




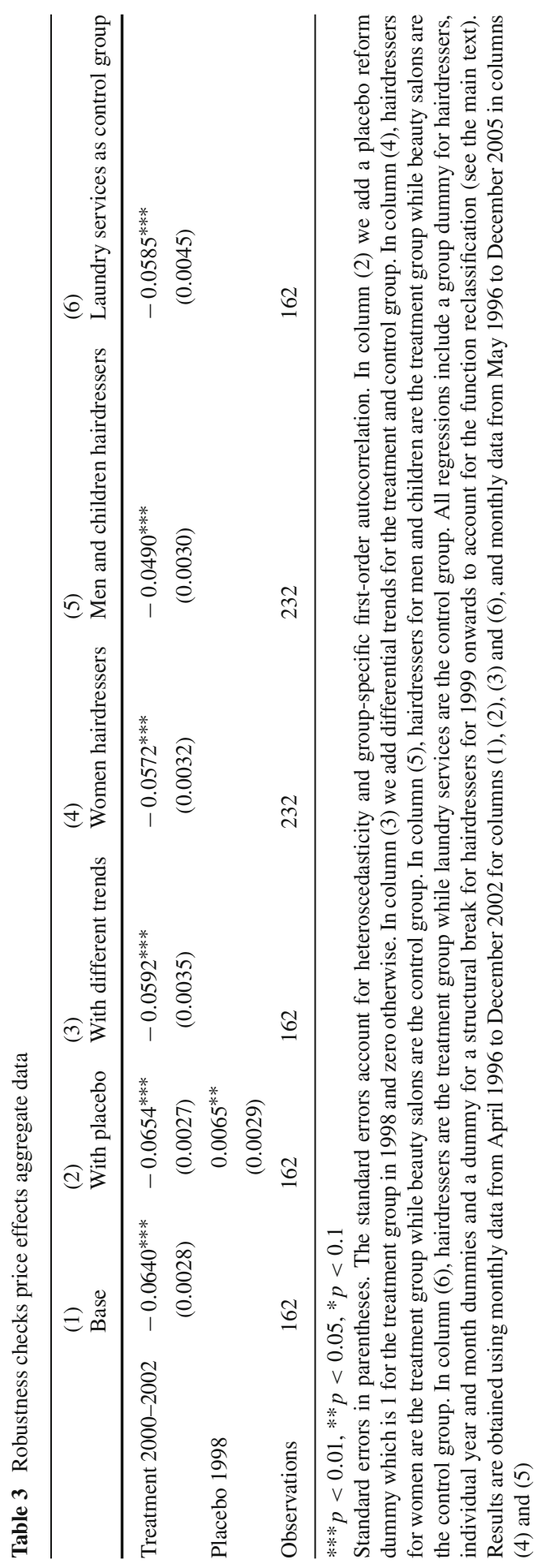


(a)

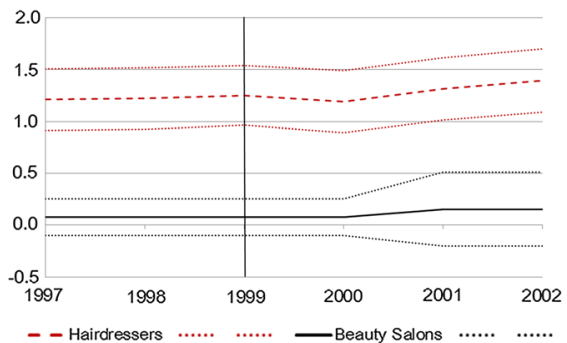

(c)

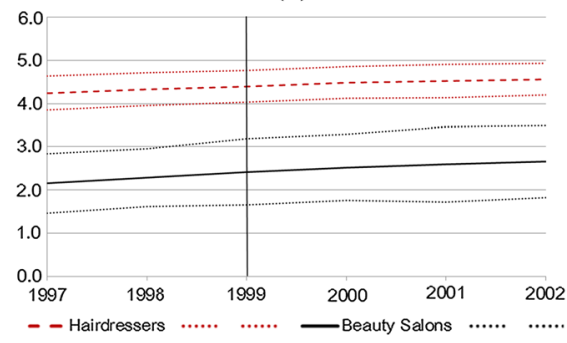

(b)

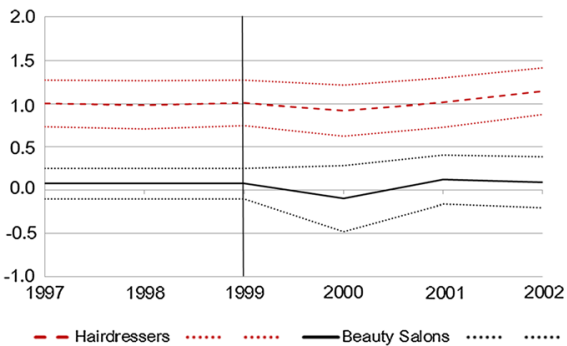

Fig. 2 Outcomes per firm for balanced panel of firms. a Employed persons. b Employed persons in FTE. c Sales. Notes Results using the Production Statistics of Statistics Netherlands. The vertical line marks the last period before the reform

there is no significant change in the treatment effect in the years after 2002, suggesting that we capture the long-run effect already in the period up to 2002. Finally, column (6) shows that when we use laundry services as an alternative control group. ${ }^{27}$ we also find near full pass-through of the lower VAT rates for hairdressing services. ${ }^{28}$

Moving from the analysis of the monthly indices to the firm-level data, Fig. 2a shows the development in the log of the average number of employed persons per firm for hairdressers, the dotted red line with $95 \%$ confidence interval, and for beauty salons, the solid black line with $95 \%$ confidence interval, for the balanced panel of firms for

\footnotetext{
27 Laundry services correspond to SBI-1993 code 93011 ( 'Wasserijen en linnenverhuur'), SBI-1993 code 93012 ('Chemische wasserijen en ververijen') and SBI-1993 code 93013 ('Wassalons en verzendinrichtingen'. The number of observations on laundry firms is too small to use as a separate control group. Unfortunately, we have no data on the other control groups considered by Kosonen (2015), like fitness clubs.

28 Following the suggestion of one of the referees, we also considered using data for hairdressers in Belgium or Germany as an alternative control group. Unfortunately, similar data for Belgium is not available for the same level of disaggregation for our data period. For Germany, we could only find monthly price indices on a national level for hairdressers and beauty salons separately, and for hairdressers only separately for men and women. Running the price regressions for women and for men and children, using women hairdressers and men hairdressers in Germany as the control group, respectively. The estimated treatment effects for prices are negative, statistically significant but smaller than our base results. However, the placebo dummy for 1998 was relatively large and statistically significant for both specifications. Hence, the assumptions of the DID seem to be violated. Including country-specific trends results in a negative treatment effect for prices of -0.0347 for Dutch women hairdressers and -0.0378 for Dutch men and children hairdressers (full regression results available on request).
} 
the period 1997-2002. We see a flat profile up to the reform and then an increase in the number of employed persons per firm in 2001 and 2002 for both the treatment and control group, with the difference somewhat increasing in 2002. A similar pattern is observed for the average number of employed persons in full-time equivalents in Fig. 2b, with a small dip in 2000 for both groups. Sales also develop rather similar for the treatment and control group, as shown by Fig. 2c.

Regression results are given in Table 4. Column (1) gives the results for the number of employed persons per firm, where we include year dummies, a firm fixed effect (which absorbs the group dummy), the structural break dummy for 1999 and beyond and the treatment dummy for 2000 and beyond. We find a tiny negative but statistically insignificant effect on the number of employed persons per firm. Column (2) gives the results for the number of persons in FTE per firm. Here we find a positive but statistically insignificant effect. For sales we again find a negative statistically insignificant treatment effect, see column (3), consistent with the results for the monthly survey data. In Column (4) we then use the estimates for sales and the results from the montly price index regressions to calculate the effect on the volume of sales, which suggests a small positive treatment effect if anything. Column (5)-(8) give the estimates for the individual treatment year dummies. The results for 2002 are more positive for employment in persons and employment in FTE, though not for sales. Overall, the firm-level data also do not provide clear evidence of a statistically and economically significant positive effect on the volume of sales, nor on the level of employment per firm, consistent with the results for the monthly indices.

Table 5 contains a number of robustness checks using the firm-level data. The placebo treatment dummy for 1998 is statistically insignificant for all outcome variables, and the treatment effect for 2002-2002 is unaffected. Inclusion of group-specific trends makes the treatment effects more negative, though still not statistically significant. $^{29}$ The number of employed persons, employed persons in FTE and the size of sales per firm is larger for hairdressers than for beauty salons, as shown by Fig. 2. When we restrict the number of employed persons (in FTE) per firm to a maximum of 10 to make the treatment and control group more comparable (although this comes at the loss of observations), we find similar small and statistically insignificant treatment effects. When we include laundry services in the control group, again we find small and statistically insignificant treatment effects. We prefer to use the balanced panel of firms, because as noted in Sect. 4 there appears to be non-random attrition in the unbalanced panel. Table 5 shows that when we use the unbalanced panel of firms (though observed at least once before and after the reform), we still find small and statistically insignificant treatment effects for employment in persons and in full-time equivalents, but the effect for sales becomes more negative though still statistically insignificant. However, when we include firm fixed-effects, the treatment effects become more positive. In particular, the treatment effect on employed persons in full-time equivalents becomes larger and statistically significant. We worry that this is due to non-random attrition (Lechner et al. 2016). Indeed, following Nijman and Verbeek (1992), we perform a (quasi-)Hausman test of the fixed effects model using the unbalanced panel

29 The number of periods is relatively short, making it hard to estimate the trends for the treatment and control group. 


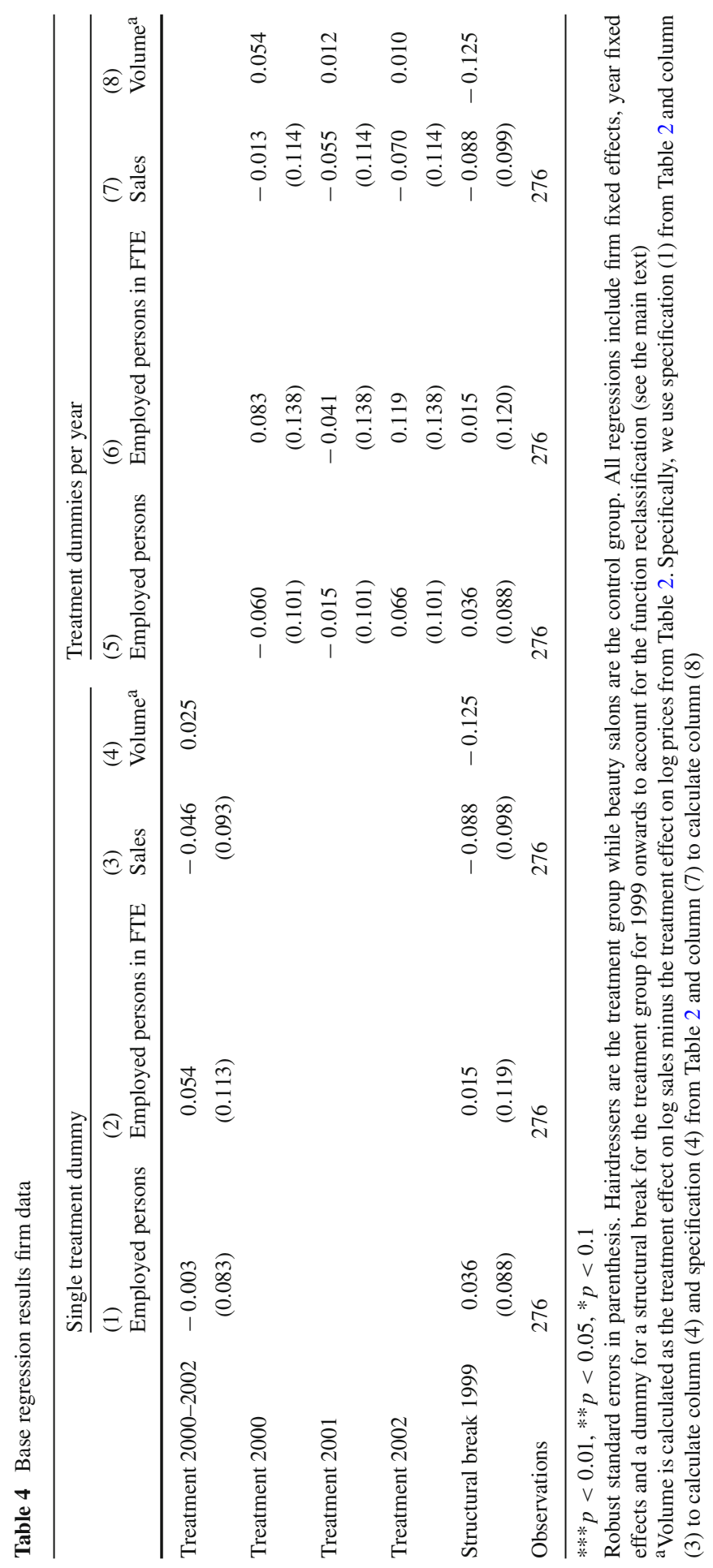


Table 5 Robustness checks firm-level data

\begin{tabular}{llll}
\hline Treatment 2000-2002 & $(1)$ & $(2)$ & $(3)$ \\
& Employed persons & Employed persons in FTE & Sales \\
\hline Base & $-0.003(0.083)$ & $0.054(0.113)$ & $-0.046(0.093)$ \\
Observations & 276 & 276 & 276 \\
With placebo Treatment 2002-2002 & $-0.003(0.083)$ & $0.054(0.113)$ & $-0.046(0.093)$ \\
Placebo 1998 & $0.010(0.102)$ & $-0.018(0.138)$ & $-0.042(0.114)$ \\
Observations & 276 & 276 & 276 \\
With differential trends & $-0.108(0.123)$ & $0.032(0.167)$ & $-0.016(0.138)$ \\
Observations & 276 & 276 & 276 \\
Only firms with < 10 employees & $-0.009(0.088)$ & $0.063(0.104)$ & $-0.031(0.102)$ \\
Observations & 228 & 228 & 228 \\
Beauty salons and laundry & $-0.024(0.061)$ & $-0.016(0.082)$ & $-0.050(0.067)$ \\
$\quad$ services as control group & & & 330 \\
Observations & 330 & 336 & $-0.139(0.241)$ \\
Unbalanced panel & $-0.022(0.170)$ & $0.069(0.064)$ & 1030 \\
w/o firm fixed effects & 1030 & 1032 & $-0.074(0.046)$ \\
Observations & $-0.012(0.039)$ & $0.093^{* * *}(0.044)$ & 1030 \\
Unbalanced panel & & & \\
with firm fixed effects & 1030 & 1032 & \\
Observations & & & \\
\hline
\end{tabular}

*** $p<0.01, * * p<0.05, * p<0.1$

Robust standard errors in parenthesis. Hairdressers are the treatment group while beauty salons are the control group. All regressions include firm fixed effects, year fixed effects and a dummy for a structural break for the treatment group for 1999 onwards to account for the function reclassification (see the main text)

against the fixed effects model using the balanced panel. Looking at the individual coefficients, we find the p-values for the null hypothesis that the coefficients for the treatment dummy are the same in both models of $0.079,0.093$ and 0.092 for employment in persons, employment in full-time equivalents and sales, respectively. Hence, we reject the null hypothesis of non-selective attrition at the $10 \%$ confidence level. Furthermore, including differential trends in the unbalanced panel with firm fixed effects again results in a small and statistically insignificant effect, see (Jongen et al. 2017, Table A.8). ${ }^{30}$

\section{Conclusion}

This paper studied the impact of a VAT cut for hairdressers in the Netherlands in 2000. Following Kosonen (2015), we use beauty salons as the main control group to assess the impact of the reform. We used survey data on average monthly prices, sales and the

\footnotetext{
30 We also considered the robustness of the results to alternative modeling assumptions. We prefer to use the fixed effects specification to using first differences because using fixed effects is typically more efficient
} 
volume of sales, and annual firm-level panel data on employment and sales per firm. Our results suggest that the VAT cut was largely passed on to consumers in the form of lower prices. Despite the drop in prices due to the reform, we do not find a statistically and economically positive effect of the reform on the volume of sales or employment. Hence, overall demand for hairdressing services seems rather unresponsive to price changes. One of the main goals of the VAT reform was to stimulate the (formal) employment of labour intensive services. Our results do not support this, though we should note that the estimated standard errors using the firm-level data are rather large given the small sample size.

It may come as a surprise that we do not find a significant positive treatment effect on the volume of sales or employment. However, this finding is consistent with the few other quasi-experimental studies that look at the effect of a VAT cut for labour intensive services. Harju and Kosonen (2014) do not find an impact on the quantity of meals after a VAT cut for restaurants in Finland and Sweden and Kosonen (2015) does not find a significant effect of a VAT cut for hairdressers in Finland on the volume of sales. The outcomes of both studies are based on much larger administrative data sets than ours. This suggests that that the limited number of observations from the firm-level survey data are not necessarily driving the outcomes.

It seems that we can never get better firm-level data and therefore more precise results for the 2000 reform at the individual firm level. We selected the Production Statistics dataset because it is the only dataset that has micro data on employment and sales several years before the reform and after the reform. This is survey data that is costly to collect and there is substantial attrition in firm-level data, so we inevitably end up with a small sample, though we do not expect this selection to bias our results. Indeed, the results for the balanced and unbalanced panel (without fixed effects) are quite similar, and the results for sales using the selected firm-level data are quite similar to the results for sales using the monthly averages (that come from a large random sample of all firms). It would be interesting to study some more recent reforms in the VAT rate-although they have been much smaller in scope-with the more recent large administrative datasets that cover the entire 'universe' of Dutch firms and workers.

\footnotetext{
Footnote 30 continued

than first differences with more than two periods, provided that the remaining error term is homoscedastic and serially uncorrelated (Angrist and Pischke 2008), and it is not clear how we could account for the structural break in 1999 due to the function reclassification when using first differences. However, one thing we can do is to estimate first differences with 1999 as the base year. Estimating the treatment effect using first differences and the years $\{1999,2000\},\{1999,2001\}$ and $\{1999,2002\}$ results in estimated treatment effects that are identical up to 3 digits to the effects reported in columns (5)-(7) in Table 4 in the main text. The estimated standard errors are also quite comparable, and no coefficient is statistically significantly different from zero. Another approach would be to use lagged dependent variables instead of fixed effects (e.g. Angrist and Pischke 2008, pp. 243-247). Using the initial value, one particular type of lagged dependent variable, instead of fixed effects results in estimated treatment effects that are again similar up to 3 digits to the effects reported in columns (1)-(3) in Table 4, with larger standard errors. Hence, the treatment effects remain statistically insignificantly different from zero.
} 


\section{References}

Angrist, J. D., \& Pischke, J.-S. (2008). Mostly harmless econometrics: An empiricist's companion. Princeton: Princeton University Press.

Benedek, D., de Mooij, R. A., \& Wingender, P. (2015). Estimating VAT pass through. IMF Working Paper No. $15 / 214$.

Benzarti, Y., Carloni, D., Harju, J., \& Kosonen, T. (2017). What goes up may not come down: Asymmetirc incidence of value added taxes. Technical report, University of California Los Angeles, Los Angeles.

CAO. (1998). Collectieve arbeidsovereenkomst voor het kapperbedrijft. Technical report.

Copenhagen Economics. (2008). Study on reduced VAT applied to goods and services in the Member States of the European Union. Technical report, Directorate General Taxation and Customs Union, European Commission.

Diamond, P. A., \& Mirrlees, J. A. (1971). Optimal taxation and public production II: Tax rules. The American Economic Review, 61(3), 261-278.

EIM. (1998). De werkgelegenheidseffecten van een BTW-verlaging op arbeidsintensieve diensten, Eindrapport. Technical report, Ministerie van Financien/Ministerie van Economische Zaken.

European Commission. (1999). Council Directive of the European Commission CD/1999/85/EC. 22 October.

European Commission. (2002). Council Directive of the European Commission CD/2002/93/EC. 3 December.

European Commission. (2003). Report from the Commission to the Council and the European Parliament. Experimental application of a reduced rate of VAT to certain labour-intensive services. Technical report, Directorate General Taxation and Customs Union.

European Commission. (2004). Proposal for a Council Directive amending Directive 77/388/EC by reason of the accession of the Czech Republic, Estonia, Cyprus, Latvia, Lithuania, Hungary, Malta, Poland, Slovenia and Slovakia. Technical report.

Harju, J., \& Kosonen, T. (2014). The inefficiency of reduced VAT rates: Evidence from the restaurant industry (Working Paper). Helsinki: VATT/Government Institute for Economic Research.

Hoofdbedrijfsschap Ambacht. (2009). Structuuronderzoek kappersbranche 2009. Technical report.

IFS, CPB, CAPP, CASE, CEPII, ETLA, IFO, \& IHS. (2011). A retrospective evaluation of elements of the EU VAT system - final report. Technical report, TAXUD, European Commission.

Jongen, E., Lejour, A., \& Massenz, G. (2017). Cheaper and more haircuts after VAT cut? Evidence from The Netherlands. Technical report, CPB Discussion Paper 368, The Hague.

Kosonen, T. (2015). More and cheaper haircuts after VAT cut? On the efficiency and incidence of service sector consumption taxes. Journal of Public Economics, 131, 87-100.

Lechner, M., Rodriquez-Planas, N., \& Fernandez Kranz, D. (2016). Difference-in-difference estimation by FE and OLS when there is panel non-response. Journal of Applied Statistics, 41(11), 2044-2052.

Nijman, T., \& Verbeek, M. (1992). Nonresponse in panel data: The impact on estimates of a life cycle consumption function. Journal of Applied Econometrics, 7(3), 243-257.

Ramsey, F. P. (1927). A contribution to the theory of taxation. The Economic Journal, 37(145), 47-61.

Seely, A. (2016). VAT: European law on VAT, Briefing Paper No. 2683, House of Commons, London.

Vrijburg, H., Mellens, M., \& Dijkstra, J. (2014). Robust estimation of the VAT pass-through in the Netherlands. Technical report, CPB Discussion Paper No. 297, The Hague. 